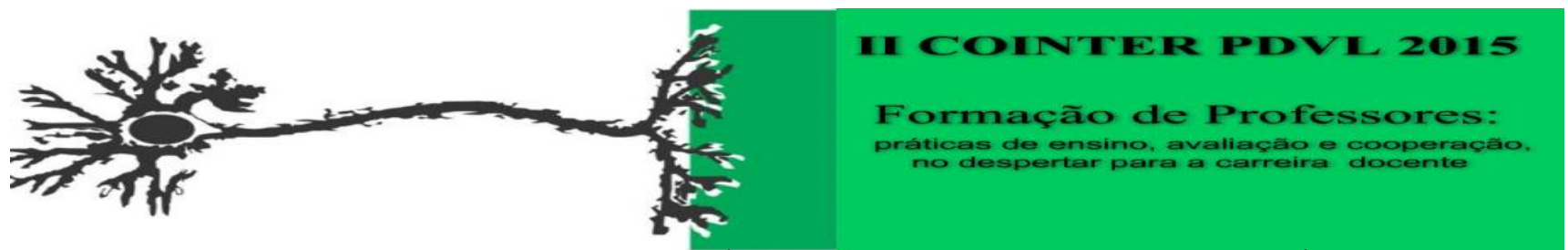

\title{
DESENVOLVENDO APLICAÇÕES LÚDICAS PARA O ENSINO DE QUÍMICA: UMA NOVA ESTRATÉGICA PARA O ENSINO
}

\author{
Apresentação: Comunicação Oral \\ Ayrton Matheus da Silva Nascimento ${ }^{1}$; Higor Diego Farias de Melo ${ }^{2}$ Rhaylene de Almeida Ramos ${ }^{3}$ \\ Maria Tatiana da Silva Santos ${ }^{4}$; Kilma da Silva Lima Viana ${ }^{5}$
}

\begin{abstract}
Resumo
Esse artigo apresenta os resultados de uma pesquisa desenvolvida em uma escola da Rede Pública do Município de Vitória de Santo Antão, Pernambuco, com estudantes do Ensino Médio. Seu objetivo foi investigar as contribuições dos jogos didáticos para a construção dos conceitos de Química do Ensino Médio. Para isso, foram aplicados jogos com os estudantes e aplicados questionários sobre a vivência. Como resultados, foi verificado o quanto os jogos auxiliaram na compreensão dos conteúdos, pois os estudantes compreenderem os conteúdos de forma mais divertida e atrativa, especialmente com relação à identificação dos subníveis de energia e da tabela periódica. Ressalta-se, assim, que os jogos "Dados Pauling" e "Dominó da Família Periódica", podem-se ser aplicados com uns dos instrumentos para auxiliar o ensino de "Distribuição Eletrônica" e "Tabela Periódica" em química geral.
\end{abstract}

Palavras-chave: distribuição eletrônica, tabela periódica, ensino de química e jogos didáticos

\section{Introdução}

A compreensão dos conteúdos da Química está relacionada com uma nova visão da ciência e do conhecimento científico que não se configura num corpo de teorias e procedimentos de caráter positivista, e sim, como modelos teóricos social e historicamente produzidos. (ZAZON et al., 2008). É notório observar que, em ambientes escolares, um número significativo de discentes apresentando dificuldades com as aplicações dos conteúdos da disciplina Química, sem utilizar outros meios metodológicos de motivarem os alunos, com isso, as aulas ficam de forma tradicional, sem inovações didáticas, e em muitas vezes os docentes se preocupam apenas em concluir a ementa sem fazer relação com o cotidiano, sendo assim aulas de Ensino Conteudista. Esse fato pode ser atribuído às estratégicas tradicionais de ensino que, aliados aos conteúdos complexos, tornam as aulas monótonas e desestimulantes.

Segundo Zanon 2008 (et al.) os jogos proporcionam ao aluno uma forma prazerosa e divertida de estudar, além de oferecer ao professor uma maneira diferente de avaliar a construção do alunado em relação aos conteúdos estudados, de revisar conteúdo ou como um meio mais dinâmico de se apropriar do conhecimento, permitindo a identificação de erros de aprendizagem.

\footnotetext{
${ }^{1}$ Licenciatura em Química, Instituto Federal de Pernambuco (IFPE - CVSA), E-mail: ayrthon.matheus@gmail.com

${ }^{2}$ Licenciatura em Química, Instituto Federal de Pernambuco (IFPE - CVSA), E-mail: higordiego@outlook.com

${ }^{3}$ Licenciatura em Química, Instituto Federal de Pernambuco (IFPE - CVSA), E-mail: rhaylene@hotmail.com

${ }^{4}$ Licenciatura em Química, Instituto Federal de Pernambuco (IFPE - CVSA), E-mail: mariatatiana015@hotmail.com

${ }^{5}$ Docente do Instituto Federal de Pernambuco (IFPE - CVSA), E-mail: kilma.viana@vitoria.ifpe.edu.br
} 
A precípua utilidade do uso de jogos didáticos envolve a motivação, desenvolvida pelo desafio, acarretando o acréscimo de estratégias de resolução de dúvidas, a avaliação das decisões tomadas e a familiarização com termos e concepções apresentadas. Os jogos pedagógicos aliam o aprendizado de determinados conteúdos à atividade lúdica, despertando interesse dos estudantes nos conteúdos discutidos e propiciando uma aprendizagem eficaz, divertida e empolgante. Por esse motivo, o jogo se torna uma peça de importância quando se quer atrair a atenção do estudante para determinado conteúdo em que ele oferece resistência. No momento em que ele encara o jogo como uma brincadeira, aprende o conteúdo sem perceber. (KISHIMOTO, 1994). No entanto, o jogo não deve ser utilizado ao acaso, mas visto como uma das atividades dentro de uma sequência definida de aprendizagens e um meio a ser usado para se alcançar determinados objetivos educacionais.

Vários autores têm enfatizado a eficiência do jogo didático, no Ensino de Química, em despertar a atenção dos estudantes, a qual é baseada no aspecto lúdico, que, geralmente, produz efeito positivo no aspecto disciplinar (SOARES; CAVALHEIRO, 2006; OLIVEIRA; SOARES, 2005; EICHLER; DEL PINO, 2000; GIORDAN, 1999; SANTOS; MICHEL, 2009). Diversos temas em Química podem ser explorados com o auxílio de jogos didáticos. Por acreditar em sua eficácia como ferramenta de apoio ao ensino, foi desenvolvido, no decorrer desta pesquisa, um jogo para o Ensino de Química. Jogos desse tipo podem contemplar alguns dos conteúdos em sala de aula com o objetivo de facilitar o entendimento e de romper com a ideia de que as aulas de Química são chatas e monótonas.

Os jogos estimulam a curiosidade, a iniciativa e a autoconfiança; aprimoram o desenvolvimento de habilidades linguísticas, mentais e de concentração; e exercitam interações sociais e trabalho em equipe (VYGOTSKY, 1989).

A aplicação de jogos didáticos no Ensino Médio pode ser um instrumento bastante avultado para tornar aulas de Química, mais atrativas e interessantes. O objetivo deste trabalho é interligar as regras dos tradicionais jogos aos conceitos do componente curricular de química dos $1^{\mathrm{o}}$ anos. Tratase de uma boa ocasião para mencionar o assunto, introduzindo definições com um pouco de diversão.

\section{Fundamentação Teórica}

Segundo Kishimoto (1994), o jogo, considerado um tipo de atividade lúdica, possui duas funções: a lúdica e a educativa, e elas devem estar em equilíbrio, pois se a função lúdica prevalecer, não passará de um jogo e se a função educativa for predominante será apenas um material didático. Os jogos se caracterizam por dois elementos que apresentam: o prazer e o esforço espontâneo, além de integrarem as várias dimensões do aluno, como a afetividade e o trabalho em grupo. Assim 
sendo eles devem ser inseridos como impulsores nos trabalhos escolares. Os jogos são indicados como um tipo de recurso didático educativo que podem ser utilizados em momentos distintos, como na apresentação de um conteúdo, ilustração de aspectos relevantes ao conteúdo, como revisão ou síntese de conceitos importantes e avaliação de conteúdos já desenvolvidos (CUNHA; 2004).

A atividade lúdica o objetivo de propiciar o meio para que o aluno induza o seu raciocínio, a reflexão e consequentemente a construção do seu conhecimento. Promove a construção do conhecimento cognitivo, físico, social e psicomotor o que o leva a memorizar mais facilmente o assunto abordado. Além isso, desenvolve as habilidades necessárias às práticas educacionais da atualidade. De acordo com Melo (2005), o lúdico é um importante instrumento de trabalho. O mediador, no caso o professor, deve oferecer possibilidades na construção do conhecimento, respeitando as diversas singularidades. Essas atividades oportunizam a interlocução de saberes, a socialização e o desenvolvimento pessoal, social, e cognitivo quando bem exploradas. Quando se cria ou se adapta um jogo ao conteúdo escolar, ocorrerá o desenvolvimento de habilidades que envolvem o indivíduo em todos os aspectos: cognitivos, emocionais e relacionais. Tem como objetivo torná-lo mais competente na produção de respostas criativas e eficazes para solucionar os problemas.

\section{Metodologia}

Campo e Sujeito: O campo de pesquisa foi uma escola de Referência da Rede Pública da cidade de Vitória de Santo Antão, Pernambuco, a EREM - José Joaquim da Silva Filho.

Instrumentos de Pesquisa: Questionários com os discentes, a construção dos jogos didáticos, além de estudos sobre inovações dos jogos didáticos para avanço do ensino e aprendizagem dos discentes.

Coleta e Análise dos Dados: Na pesquisa foram analisadas: as aulas na EREM - José Joaquim da Silva Filho, Parâmetros Curriculares Nacionais para o Ensino Médio, o questionário foi analisado por meio da estatística descritiva, utilizando-se da distribuição de frequência. Ressaltamos que foram considerados os questionários aplicados durante as intervenções e os resultados obtidos dos participantes que concordaram com a pesquisa e assinaram o Termo de Consentimento Livre e Esclarecido - TCLE.

\section{Dados Pauling \\ Regras do Jogo}

- $\quad$ O jogo deve ser realizado no mínimo de 02 a 04 equipes;

- Inicia lançando o dado 01 as 04 equipes e o número maior começará o jogo; 
- $\quad$ Primeiro lança o dado 01, (Níveis de Energia), apresenta 06 lados, sendo eles 1, (2,7), 3, 4, 5 e 6, cada lado apresenta cores distintas, devido ao subnível que cada nível pode-se atribui, a figura 01 informa as cores;

- Na sequência, o dado 02 (Subníveis de Energia), depende do subnível (s,p,d,f) (se for s o dado 03, se for p o 04, se for d o 05, se for o f o 06) e assim indicará o subnível e fará a distribuição eletrônica, e em seguida observar a quantidade de elétrons (e`), e vê na tabela periódica qual o nome do elemento químico, o símbolo e mostra o Cartão do Elemento Químico;

- Cada equipe tem apenas 180 segundos para responder a distribuição eletrônica, a quantidade de elétrons (e $\mathrm{e}^{-}$), o nome do elemento químico e o símbolo. Assim, se o grupo não responder, não ganha ponto. $\mathrm{O}$ grupo que ao término do jogo obtiver maior pontuação será o vencedor. Durante as 04 primeiras partidas, as equipes terão acesso a distribuição eletrônica.

- No caso a equipe acertar a distribuição, o nome e o símbolo, o professor deve, ainda, adotar a função de mediador entre as equipes, comentando sobre a distribuição, a quantidade de elétrons (e`), nome e o símbolo do elemento químico, elucidar possíveis dúvidas e também motivando a discussão e exposição de diferentes pontos de vista.

\section{Dominó da Família Periódica}

\section{Regras do Jogo}

- $\quad$ O jogo deve ser realizado no mínimo de 02 a 04 pessoas;

- $\quad$ Em seguida formar 08 equipes;

- Inicia embaralhando todo dominó;

- $\quad$ A dupla ou o indivíduo que terminar primeiro ganha;

- $\quad$ Em caso que os jogadores fiquem no final do jogo com peças, vão contar pontas, por conseguinte soma o número atômico de todas as peças restantes;

\section{Resultados e Discussão}

\section{Jogos Didáticos - Dados Pauling}

O Dados Pauling é um jogo que é bastante famoso em todo ambiente, o dado é formado por 06 dados de seis faces como mostra a figura 01. Cada dado representa uma parte do conteúdo Distribuição Eletrônica, representado por número quântico principal (n) ou níveis de energia, números quânticos secundários (l) ou subníveis de energia, quantidade de elétrons (e`) obtidas nos subníveis s, p, d e f. O dado 01 refere-se ao número quântico principal (n) ou níveis de energia, 
sendo assediado os níveis: 1, (2,7) 3, 4, 5, 6. O dado 04 indica o número quântico secundário (l) ou subníveis de energia, sendo: s, p, d e f. Os dados 2,3,5,6 é referente a quantidade de elétrons (e`) que o subnível $\boldsymbol{s}, \boldsymbol{p}, \boldsymbol{d} \boldsymbol{e} \boldsymbol{f}$ pode suportar. O jogo foi, ainda, complementado com cartas informativas sobre cada Elemento Químico, Número Atômico (Z).
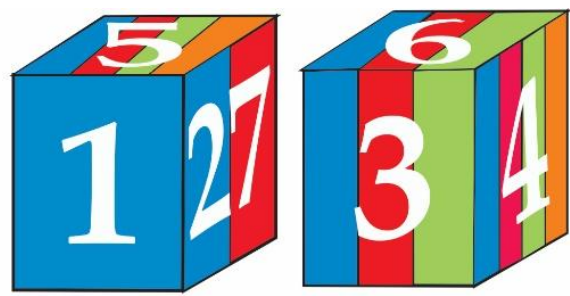

Dado 01

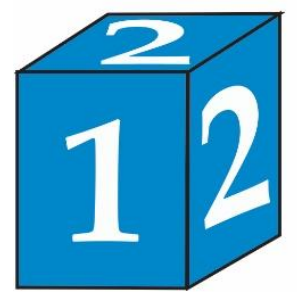

Dado 03

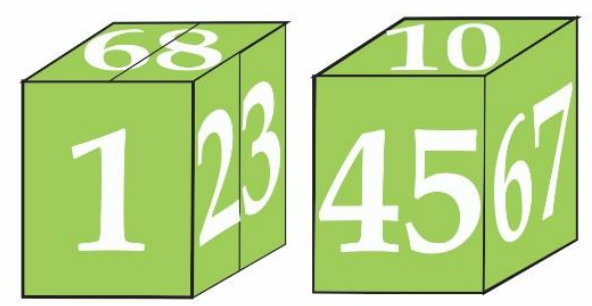

Dado 05

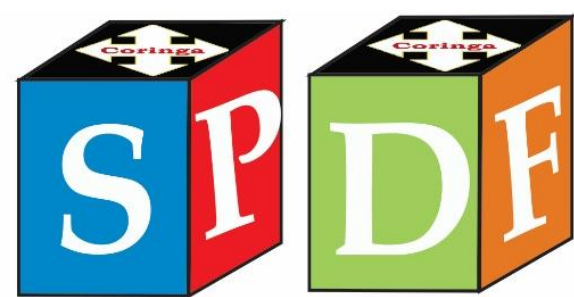

Dado 02

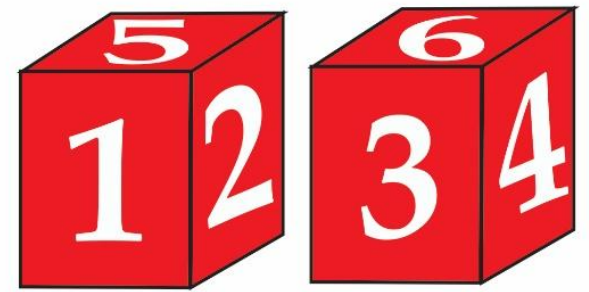

Dado 04

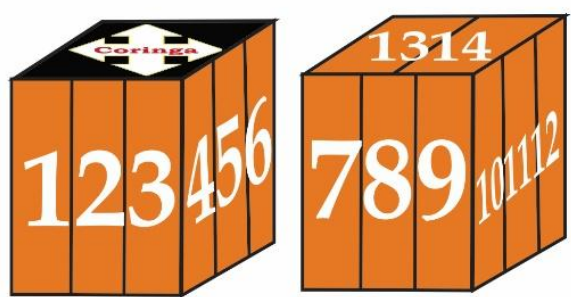

Dado 06

Figura 01: Ilustração dos Dados

Para avaliar a contribuição do jogo no processo de ensino e aprendizagem dos estudantes, foram aplicados pré-diagnósticos referente ao conteúdo de "Distribuição Eletrônica", sendo assim as questões: (1) Qual é a distribuição eletrônica do átomo ${ }_{26} \mathrm{Fe}^{56}$ ? (2) Faça a distribuição eletrônica até o subnível $\mathbf{4} \mathbf{s}^{\mathbf{1}}$, ache a sua quantidade de elétrons, e o elemento química e o símbolo; (3) Qual a estrutura eletrônica, em ordem geométrica, de um elemento químico de número atômico 77? (4) O bromo, que nas condições ambientes se encontra no estado líquido e é formado por átomos representados por ${ }_{35} \mathrm{Br}^{80}$, faça a distribuição eletrônica, e ache quantos níveis de energia tem? (5) Quantos elétrons possui o subnível $\mathbf{3} \mathbf{p}^{\mathbf{5}}$ ?

No caminhar da atividade, a sala foi dividida em duas equipes, indicando um líder para ter a responsabilidade de motivar os outros a executarem a atividade. No pré-diagnóstico, os estudantes responderam 05 questões e houve uma grande diferença em relação ao pós-diagnóstico, no prédiagnóstico a quantidade de questões respondidas foram: (1ª Questão) 69 responderam, e 173 não 
responderam, na (2 ${ }^{\mathbf{a}}$ Questão) 16 responderam e 226 não responderam, na (3 ${ }^{\mathbf{a}}$ Questão) 38 responderam e 204 não responderam, na (4ª Questão) 22 responderam e 220 não responderam, na (5 $5^{\text {a }}$ Questão) 51 responderam e 191 não responderam, em relação ao pós-diagnóstico (1ª Questão) 168 responderam e 74 não responderam, na ( $2^{\mathbf{a}}$ Questão) 197 responderam e 45 responderam, na ( $3^{\text {a }}$ Questão) 151 responderam e 91 não responderam, na (4ª Questão) 136 responderam e 106 não responderam, na (5 $\mathbf{5}^{\mathbf{a}}$ Questão) 144 responderam e 98 não responderam. Com base nos resultados dos diagnósticos, pré e pós da utilização do meio, a partir dos dados acima, analise-se que os discentes aprimoraram significativamente seu desempenho relacionada a temática abordada.

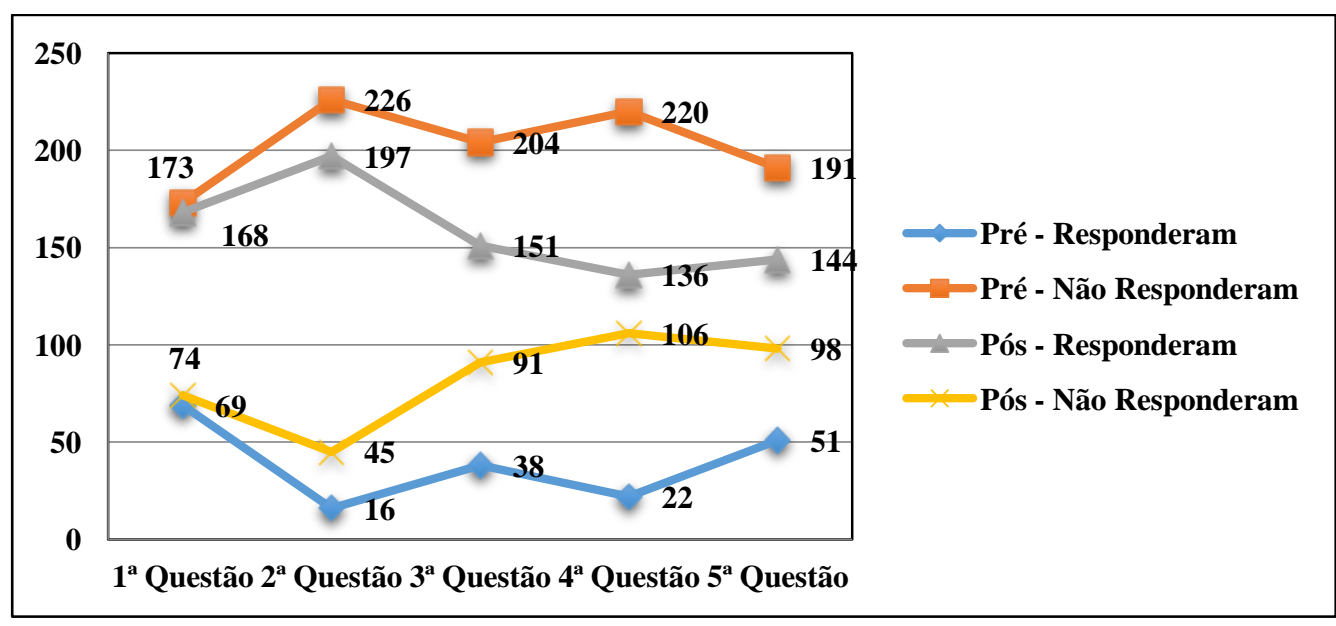

Figura 02: Resultados do Pré e Pós Diagnósticos

\section{Dominó da Família Periódica}

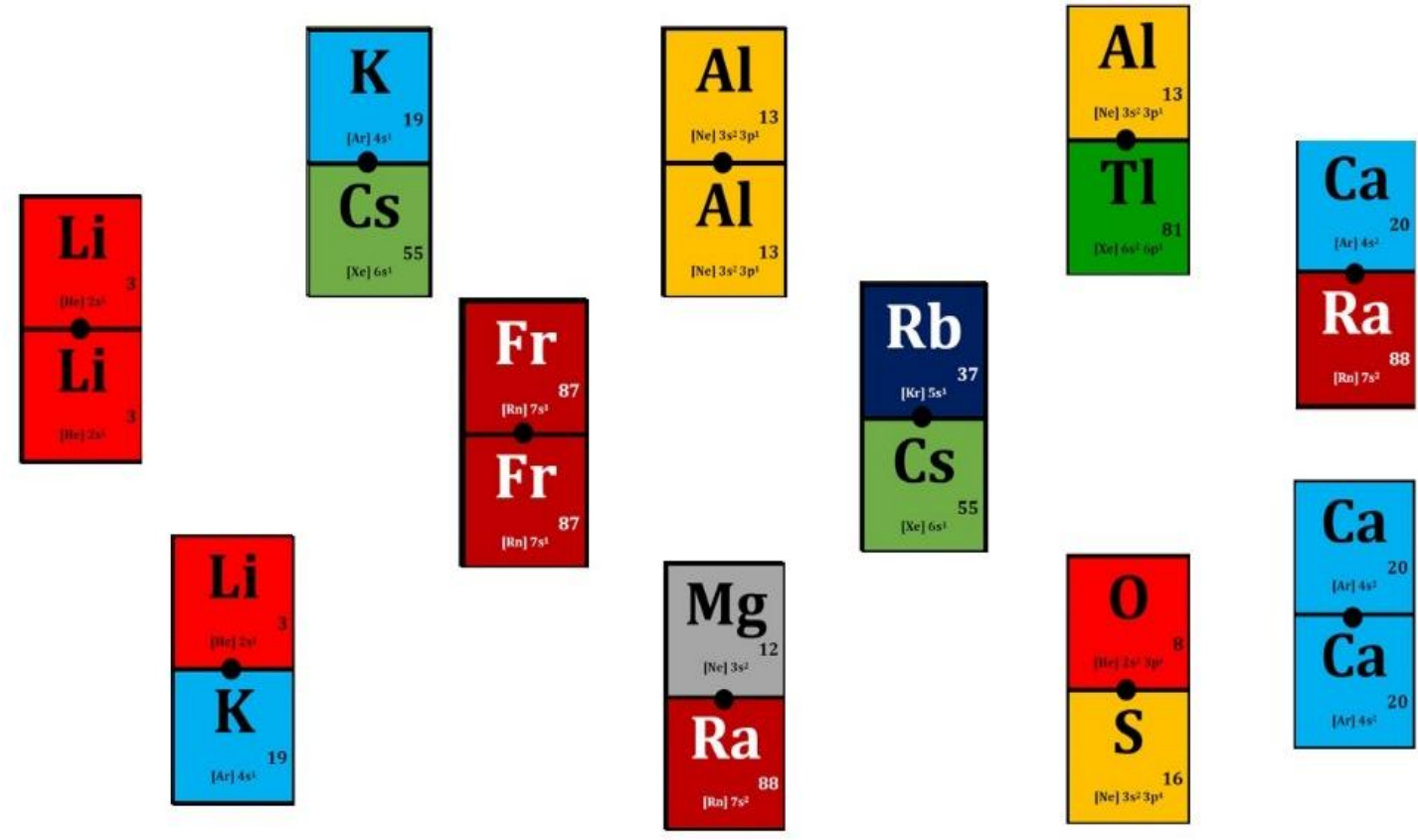

Figura 03: Ilustração do Dominó 
O Dominó da Família da Tabela Periódica (Figura 03) é um jogo que muito importante no período em que está aplicando o conteúdo de Tabela Periódica, o dominó apresenta a mesma configuração do dominó atual, contendo 28 peças, mas apresentando 08 paradigmas distintos, sendo cada um formado por cada Família ou Grupo, neste caso são: Família dos Metais Alcalinas (ns ${ }^{1}$ ), Família dos Metais Alcalinos Terroso $\left(\mathrm{ns}^{2}\right)$, Família do Boro $\left(\mathrm{ns}^{2} \mathrm{np}^{1}\right)$, Família do Carbono $\left(\mathrm{ns}^{2}\right.$ $n p^{2}$ ), Família do Nitrogênio $\left(n s^{2} n p^{3}\right)$, Família dos Calcogênios $\left(n s^{2} n p^{4}\right)$, Família dos Halogênios $\left(n s^{2} n p^{5}\right)$ e a Família dos Gases Nobres $\left(n s^{2} n p^{6}\right)$.

Para avaliar a contribuição do jogo no processo de ensino e aprendizagem dos estudantes, foram aplicados Avaliação Diagnóstica I e II referente ao conteúdo de Tabela Periódica.

Na Avaliação Diagnóstica I os alunos responderam 05 questões e houve um diferença avassaladora em relação a Avaliação Diagnósticas II, na Avaliação Diagnóstica I a quantidade de questões respondidas foram: (1 $\mathbf{1}^{\mathbf{a}}$ Questão) 119 responderam, e 71 não responderam, na ( $\mathbf{2}^{\mathbf{a}}$ Questão) 102 responderam e 88 não responderam, na ( $3^{\text {a }}$ Questão) 163 responderam e 27 não responderam, na (4 ${ }^{\mathbf{a}}$ Questão) 151 responderam e 39 não responderam, na (5 $\mathbf{5}^{\mathbf{a}}$ Questão) 105 responderam e 85 não responderam, em relação a Avaliação Diagnósticas II (1 $\mathbf{1}^{\mathbf{a}}$ Questão) 157 responderam e 33 não responderam, na ( $2^{\mathbf{a}}$ Questão) 146 responderam e 44 responderam, na ( $3^{\mathbf{a}}$ Questão) 167 responderam e 21 não responderam, na (4ª Questão) 166 responderam e 24 não responderam, na (5 $\mathbf{5}^{\mathbf{a}}$ Questão) 140 responderam e 50 não responderam. Com base nos resultados dos diagnósticos, Avaliação Diagnóstica I e na Avaliação Diagnósticas II da utilização do meio, a partir dos dados acima, analise-se que os discentes aprimoraram significativamente seu desempenho relacionada a temática abordada.

Assim, pode-se verificar também o que o dominó da família da tabela periódico como jogo didático que contribui positivamente no processo da aprendizagem dos estudantes.

$\mathrm{Na}$ literatura podemos observar que o Ensino de Química tem passado por dificuldades no processo de transpassar o conhecimento para os estudantes, isso implica um fracasso no ensino e aprendizagem desta área. Então foram aplicadas aos estudantes nesta intervenção duas Avaliações Diagnósticas I e II, sendo que umas das indagações foram em relação ao sentimento do componente curricular de Química, dividindo em cincos respostas que são: MT - Muito Satisfeito; S - Satisfeito; PI - Parcialmente Insatisfeito; IN - Insatisfeito e MIN - Muito Insatisfeito, então podemos observar a figura 04 que os resultados foram bastantes asseverativo. 


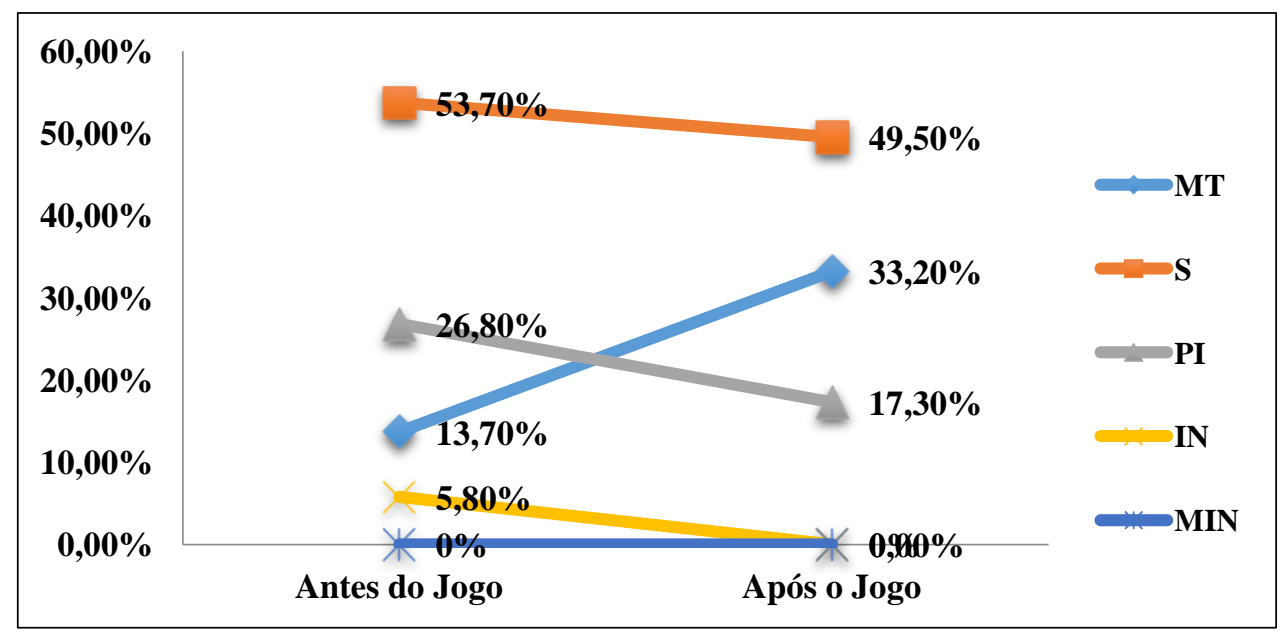

Figura 04: Percepção dos alunos em relação ao componente curricular de Química

\section{Conclusões}

Conclui-se, portanto, que o jogo didático é um instrumento que ajuda aos discentes a compreenderem os conteúdos de forma mais divertida e atrativa, percebeu-se grande entusiasmos durante as atividades realizadas. Essa ferramenta ajudou no processo de ensino-aprendizagem no Ensino de Química que contribui para que os discentes do Ensino Médio identifiquem os subníveis de energia, e realizando a distribuição eletrônica de qualquer elemento químico, através de uma forma fácil. Os jogos "Dados Pauling" e o "Dominó da Família Periódica" podem-se ser aplicados com uns dos instrumentos para auxiliar o ensino de "Distribuição Eletrônica" e de "Tabela Periódica" em química geral, já que se alcançarão os objetivos dessas atividades, ou seja, foram obtidos resultados satisfatórios em relação ao aprendizado dos discentes após a utilização desse jogo como auxílio pedagógico. Teve seu objetivo realizado, visto que sua missão educativa foi analisada durante a utilização, associando-se ao jogo a apresentação lúdica, com a finalidade de ampliar técnicas importantes para o processo de ensino-aprendizagem de Química, favorecendo, assim, a percepção de conceitos complexos e impalpável e entusiasmar a motivação, o raciocínio e a relação entre discentes e docente. E as aulas de Química ficaram mais interessantes, divertidas e descontraídas.

\section{Referências}

CUNHA, M. B. Jogos de Química: Desenvolvendo habilidades e socializando o grupo. Eneq 0282004.

EICHLER, M.; DEL PINO, J. C. Carbópolis: um software para educação química. Química Nova na Escola. n. 11, 2000, p. 10-12. Disponível em: <http://qnesc.sbq.org.br/online/qnesc11/v11a02.pdf >. Acesso em: 18 abril de 2014. 
GIORDAN, M. O papel da experimentação no ensino de ciências. Química Nova na Escola. n. 10, p. 43-49, 1999.

KISHIMOTO, T. M. Jogo, Brinquedo, Brincadeira e a Educação. São Paulo: Cortez, 1996. 183p.

MELO,C. M.R. As atividades lúdicas são fundamentais para subsidiar ao processo de construção do conhecimento. Información Filosófica. V.2 n¹ 2005 p.128- 137.

OLIVEIRA, A. S.; SOARES, M. H. F. B. Júri químico: uma atividade lúdica para discutir conceitos de química. Química Nova na Escola, n. 21, p. 18-24, 2005.

SANTANA, E. M. A influência de atividades lúdicas na aprendizagem de conceitos químicos. Instituto de Física, USP, 2006. Disponível em: http://www.senept.cefetmg.br/galerias/Arquivos_senept/anais/terca_tema1/TerxaTema1Artigo4.pdf . Acessado em 28 de Setembro de 2015.

SOARES, M.; Jogos e Atividades Lúdicas no Ensino de Química: Teoria, Métodos e Aplicações. In: Anais do XIV Encontro Nacional de Química (XIV ENEQ) 14. Curitiba. 2008.

SOARES, M. H. F. B. O Lúdico em química: jogos e atividades aplicados ao ensino de química. 203f. Tese. (Química). Universidade Federal de São Carlos: São Carlos, 2004.

VYGOTSKY, L.S. A formação social da mente. São Paulo: Martins Fontes, 1989.

ZANON, D. A. V.; GUERREIRO, M. A. S.; OLIVEIRA, R. C. Jogo didático Ludo Químico para o ensino de nomenclatura dos compostos orgânicos: projeto, produção, aplicação e avaliação. Ciências \& Cognição, v. 13, n. 1, p. 72-81, 2008. 